\title{
BIM in a Junior Enterprise of a Brazilian University: Application and Analysis
}

\author{
Lucas Willian da Silva Ruiz \\ Universidade Federal de Mato Grosso do Sul | Brasil | lucaswsr@hotmail.com
}

\begin{abstract}
Alberta Cristina Vasconcelos de Melo
Instituto Federal do Sertão Pernambucano, Universidade Federal de Mato Grosso do Sul | Brasil | alberta.melo@ifsertao-pe.edu.br
\end{abstract}

\author{
Mayara Dias de Souza \\ Universidade Federal de Mato Grosso do Sul | Brasil | mayara.dias@ufms.br
}

Pedro Henrique Silva Neves

Universidade Federal de Mato Grosso do Sul | Brasil | phs.neves@hotmail.com

\begin{abstract}
This article analyses the applications of BIM in a project developed in a junior enterprise of a Brazilian university. The study includes a bibliographical research of an empirical study to analyze a multidisciplinary project mediated by BIM. The results pointed to the benefits of a collaborative BIM project, including the production of a precise documentation, verification of interferences and compatibilization between disciplines. The experience in the junior enterprise may assist other universities to adopt BIM in the academic formation as an alternative to the absence of the subject in the curriculum.
\end{abstract}

Keywords: BIM; Project; Collaboration; Compatibilization; Multidisciplinary

\section{INTRODUÇÃO}

Processos colaborativos se configuram como princípios fundamentais para o desenvolvimento de projetos, embora no contexto atual da indústria da Arquitetura, Engenharia, Construção e Operação (AECO) ainda vigore uma fragmentação nas atividades dos profissionais envolvidos. A alteração deste cenário, com a implementação de inovações tecnológicas, dentre elas o Building Information Modeling (BIM), exigem que profissionais, processos e tecnologias enfrentem novos desafios relacionados tanto a capacitação no uso de novas ferramentas, como a busca pela integração das equipes participantes nos processos de projeto, construção e operação de empreendimentos.

Como o BIM se trata de uma inovação disruptiva, e de certa forma recente, o número de profissionais que efetivamente utilizam o BIM colaborativo em seus fluxos projetuais é ainda bastante restrito e, conforme Barison e Santos (2011) e Herr e Fischer (2018), existe uma dificuldade em encontrar pessoal qualificado. Um esforço por parte do governo brasileiro para estimular a capacitação dos profissionais e a integração do BIM na indústria $A E C O$ brasileira, foi feito com a entrada em vigor do decreto $n^{\circ}$ 9.983/19, que dispõe sobre a Estratégia Nacional de Disseminação do BIM e institui o Comitê Gestor da Estratégia da Modelagem da Informação da Construção.

Cabe destacar que, para os $9,2 \%$ das empresas do setor AECO nacional citados pelo Instituto Brasileiro de Economia (IBRE, 2019) da Fundação Getúlio Vargas (FGV) possam aumentar a utilização da modelagem em suas rotinas de trabalho é necessário investimento na formação dos futuros profissionais desta indústria. Ainda são muitas as barreiras no Brasil, sendo uma delas, as limitações decorrentes da ausência de pessoal capacitado para ensinar o conceito BIM na academia (CHECCUCCI, 2019), o que leva a não atualização dos currículos vigentes. A restrição do ensino de BIM nos cursos de Arquitetura e Engenharia Civil nas universidades brasileiras é um dos fatores que tem dificultado a implantação, adoção e difusão do conceito BIM no Brasil. Confirmando o atraso acadêmico brasileiro, BecerikGerber, Gerber e Ku (2011) já indicavam que a maioria dos programas de engenharia e arquitetura nos Estados Unidos iniciaram a oferta de cursos BIM entre o período de 2006 a 2009.

Ruschel, Andrade e Morais (2013) também abordaram que a implementação do estudo da modelagem no Brasil, era predominantemente introdutório e restrito, com uma abordagem pontual que considerava somente algumas das disciplinas do currículo, sem foco nas ferramentas de gerenciamento e de simulações do BIM, além de não abordarem todo o ciclo de vida da edificação. Isso aconteceu porque o modelo de ensino ainda está baseado em disciplinas isoladas, em que cada uma trata de assuntos específicos e especializados de forma fragmentada (CHECCUCCl et al., 2013) sem que haja, também na grande maioria dos casos, integração e colaboração, o que caracterizaria e reforçaria a complexidade do conceito contemplado pelo BIM. 
Eadie, Browne, Odeyinka, Mckeown e Mcniff (2013) verificaram que os principais impactos da implementação de BIM em organizações envolvem, dentre outros, a colaboração e o entendimento da adoção de BIM como um processo. Desta forma, a implementação BIM deve ser tratada como uma nova metodologia projetual e de gerenciamento da informação.

Atualmente, os cursos de arquitetura e urbanismo, engenharia elétrica e engenharia civil da Universidade Federal de Mato Grosso do Sul (UFMS) não possuem o BIM em suas grades curriculares. Isso mostra o descompasso da academia em relação ao mercado de trabalho que possui uma alta demanda por profissionais com essas habilidades. Uma possibilidade de inserção do BIM no meio acadêmico é através do contexto de uma Empresa Júnior (EJ), oportunizando discentes a aplicarem os conhecimentos adquiridos na graduação em um projeto real, de forma colaborativa, dado o ambiente de trabalho em grupo e de integração de diferentes disciplinas, que é inerente a uma EJ.

Uma EJ é uma associação civil com fins educacionais e sem fins lucrativos, formada exclusivamente por alunos do ensino superior ou técnico, regulamentada no Brasil através da Lei 13.267/2016 e obrigatoriamente toda a EJ deve estar atrelada a pelo menos uma Instituição de Ensino Superior (IES) e a pelo menos um curso de graduação sendo que diferentes cursos podem fazer parte do mesmo projeto (BRASIL, 2016). Uma EJ, no entanto, possui autonomia para receber pagamento pelo desenvolvimento de produtos e prestação de serviços, desde que acompanhados por docentes orientadores da IES. Essa conjuntura diferencia uma EJ de uma empresa convencional e/ou sênior, pois a empresa Jr. também como as demais citadas, precisa estar inscrita no Cadastro Nacional da Pessoa Jurídica (CNPJ). Salienta-se que essas características que definem uma EJ são importantes pois a adoção do BIM em uma organização requer alocação de recursos financeiros para atualização da infraestrutura tecnológica e/ou a necessidade de capacitação de discentes e dos docentes envolvidos na correção dos projetos dado a dependência desse profissional para atuação da empresa.

A empresa júnior em questão é a Engefour Jr tem por missão "ser uma resposta à sociedade com projetos de alto impacto por meio de uma cultura forte e profissional". A empresa vem atuando no mercado desde 2015 e conta com mais de 110 projetos já realizados nas áreas de engenharia ambiental, civil, elétrica, arquitetura e urbanismo. O desenvolvimento das suas atividades sustenta-se em um ambiente de trabalho colaborativo, estimulando uma comunicação transparente e uma cultura empresarial forte. Dessa forma, as empresas juniores possuem características tanto da academia como do mercado de trabalho, situando-se como um intermédio entre os dois grupos.

Até então o desenvolvimento dos projetos na Engefour Jr. aconteciam da forma tradicional, com a utilização do sistema CAD. A adoção do BIM exigiu uma abordagem diferente com relação ao processo projetual dos diferentes participantes, tendo em vista que em um processo tradicional CAD, cada disciplina é desenvolvida individualmente sendo ajustada ao longo da elaboração dos projetos, contrariamente ao proposto pelo BIM, que baseia-se em conceitos de trabalho colaborativo e partilha de dados e de informações. Com uma carta de serviço multidisciplinar existiu a necessidade por processos mais colaborativos para conciliar e resolver as problemáticas de cada projeto. A decisão de utilizar o BIM na EJ visou aumento da produtividade, da assertividade, do controle com relação às revisões e possibilidade de compatibilizar os diferentes projetos por meio de um fluxo de projeto único.

Uma das diferenças da mudança da utilização predominante do CAD em relação ao uso do BIM foi a facilidade de visualizar e compreender o projeto de uma área diferente e como cada elemento se inter-relaciona no modelo, como uma simulação da obra construída. Isso possibilitou a identificação das interferências com maior facilidade de compreensão e a resolução desses problemas em todas as fases do projeto. O processo BIM também tornou mais clara e precisa a comunicação das informações e intenções projetuais, assegurando a tomada de decisão. A interação com os outros participantes também foi simplificada.

Assim, o presente artigo tem por objetivo discutir o desenvolvimento do projeto multidisciplinar e colaborativo mediado pelo BIM e identificar aspectos potencializadores e limitantes do trabalho colaborativo em questão.

\section{METODOLOGIA}

A metodologia utilizada neste artigo caracteriza-se como qualitativa, e quanto à natureza do seu objetivo é exploratória descritiva. Para alcançar os objetivos propostos, o trabalho foi estruturado em quatro etapas (Figura 1), com as seguintes técnicas de coleta de dados:

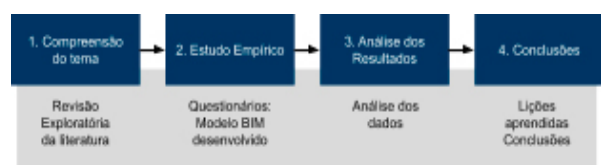

Figura 1: Etapas da Pesquisa.

Para a compreensão do tema foi realizada uma revisão da literatura sobre o conceito de empresas juniores, adoção do BIM pelas organizações e a formação dos futuros profissionais pelas universidades sendo que parte desta revisão está apresentada na Introdução deste artigo. 0 estudo empírico dividiu-se em duas etapas, cada uma visando a obtenção de dados específicos, para tal utilizouse de técnicas distintas, sendo:

a. Caracterização da equipe da Engefour Jr: verificação da opinião dos discentes responsáveis pelo desenvolvimento do projeto piloto de uma residência unifamiliar (área $=243 \mathrm{~m}^{2}$ ) com relação aos processos utilizados e a operação das ferramentas na produção dos desenhos, suas vantagens e desvantagens por meio de questionário misto (questões abertas e questões fechadas) aplicado digitalmente com suporte da ferramenta Google Formulários.

b. Análise do desenvolvimento de um projeto multidisciplinar e colaborativo mediado pelo BIM na EJ de uma Universidade brasileira: apresentação do processo de desenvolvimento dos modelos BIM. 
Após a coleta dos dados, deu-se início à análise dos resultados: questionários, fluxos de trabalho desenhados e os modelos BIM foram analisados, a fim de avaliar os aspectos potencializadores e limitantes do trabalho colaborativo em questão. Por fim, na última etapa foram apresentadas as conclusões e as lições aprendidas com este estudo.

\section{RESULTADO}

\section{CARACTERIZAÇÃO DA EQUIPE}

Para dar resposta às questões de investigação relacionadas ao estado atual de adoção e aplicabilidade do BIM na EJ em questão, utilizou-se a estratégia de aplicação de questionário. No total foram sete (07) os participantes entre discente e docentes, que atuaram diretamente no desenvolvimento do projeto referência. Logo, essa seção tem o objetivo de discutir os resultados obtidos através da análise de gráficos gerados de acordo com as respostas dos participantes com relação aos processos utilizados e a operação das ferramentas na produção dos desenhos, suas vantagens e desvantagens.

Com relação a formação dos participantes tem-se que a maioria deles na época do desenvolvimento do projeto piloto cursava engenharia civil cerca de $57,1 \%$ (4 participantes) seguido por engenharia elétrica com $28,6 \%$ (2 participantes) e apenas 14,3\% (1 participante) cursava arquitetura e urbanismo.

Com relação ao semestre do curso que os participantes estavam durante o desenvolvimento do projeto em questão tem-se que a maioria dos respondentes, cerca de $57,1 \%$ (4 alunos) cursava o $10^{\circ}$ período, seguido pelas respostas no $9^{\circ}$, no $7^{\circ}$ e no $5^{\circ}$ período, respectivamente com $14,3 \%$ (1 aluno) cada um. Observa-se a partir destes dados que todos os alunos já estavam na metade de seus cursos no desenvolvimento do projeto, apontando para a necessidade de uma maturidade maior do conhecimento dos aspectos relativos à indústria AECO como a elaboração de soluções.

Na questão acerca do nível de contato com o BIM antes do início do projeto, os participantes foram indagados com três afirmações, devendo ser atribuídas o seu grau de importância em relação às mesmas. O grau de importância foi dividido numa escala crescente de 1 a 3 , sendo 1 pouco contato e 3 bastante contato/experiência. Ao final foi feita uma média entre as afirmações, chegando ao resultado apresentado na. Verificou-se que todos os discentes já tinham tido contato com o BIM, mas que apenas $14,3 \%$ (que representa 1 participante) já tinha bastante contato até o início do desenvolvimento do projeto de referência. Mesmo assim, de modo geral todos responderam positivamente ao processo, inclusive os que tinham pouco contato, visto que durante o desenvolvimento do projeto percebeu-se o crescimento coletivo das equipes no que diz respeito à qualidade dos entregáveis, eficiência do fluxo de trabalho e no domínio geral da metodologia.

Segundo Barison e Santos (2011), a implantação do BIM implica na determinação de vários cargos responsáveis por desempenhar diferentes funções relacionadas ao edifício virtual, tais como o gerente BIM, o facilitador BIM, o analista BIM e o modelador BIM. Com isso questionouse acerca da definição de papéis e responsabilidades dentro da equipe de projeto. Destaca-se que todos responderam de acordo com as atividades desempenhadas e um dos respondentes atuou como orientador e responsável técnico e outro participante como o gerente de projetos. Um dos fatores que diferenciam uma EJ de outros tipos de empresa é justamente o fato de que necessitam do acompanhamento e aprovação de uma profissional habilitado que é o responsável técnico cuja função é orientar e revisar os projetos, isso mantém a qualidade técnica dos projetos realizados pelos alunos. Para isso os membros se reuniam com os orientadores semanalmente ou quinzenalmente para discutir e revisar os projetos ou via e-mail, dependendo da disponibilidade do orientador. Os orientadores não possuíam conhecimento do método BIM, portanto analisavam as pranchas e os arquivos no formato DWG esses gerados a partir do modelo BIM. Porém isso não limitou a produtividade ou diminuiu a qualidade técnica do projeto, pois a geração de documentação 2D (PDFs e DWGs) é realizada de forma dinâmica. Além dessas revisões, o orientador também assina o termo de responsabilidade técnica do projeto, pois os alunos não possuem registros nos conselhos regionais de cada profissão, sendo as taxas desses processos pagas pela EJ.

Depois, levantou-se a questão com relação a capacitação com objetivo de verificar se os participantes precisaram se aprofundar no BIM ou quanto a algum outro assunto específico da sua área durante 0 processo de desenvolvimento do projeto, sendo que a maioria $(57,1 \%)$ dos participantes respondeu que necessitou de alguma capacitação no período. Conforme ASBEA (2015) a capacitação dos envolvidos no processo de projeto é um ponto fundamental quando da intenção de se adotar o uso do BIM em uma organização. Como a EJ não objetiva a geração de lucro, tem-se que os recursos advindos dos serviços prestados com a realização dos projetos é revertido em capacitação dos membros por meio de cursos, eventos ou com investimento na infraestrutura para a sede da empresa.. Durante o desenvolvimento desse projeto foi necessário cursos de capacitação para os softwares utilizados buscando aumentar a qualidade técnica dos projetos realizados pelos discentes. Os cursos online de capacitação se mostraram muito eficientes para os participantes que alegaram não ter experiência com o BIM e sentiram-se mais confiantes com a utilização da ferramenta após o curso. Conforme CBIC (2016), é importante a definição inclusive de um plano de treinamento e capacitação, sendo essa uma condição considerada crítica e fundamental dado a falta de profissionais qualificados e experientes.

Com relação aos softwares, foi elaborada uma questão direcionada com objetivo de verificar qual(is) software(s) os participantes utilizaram durante o desenvolvimento do projeto. Através da análise do gráfico verifica-se que o software mais utilizado por parte dos participantes foi o Autodesk Revit $(57,1 \%)$, seguido pelo AutoCAD (42,8\%). Os outros softwares utilizados correspondem ao Cypecad e Excel. Vale salientar que a maioria dos respondentes utilizaram mais de um software em seus fluxos de trabalho. O AutoCAD foi apontado como complemento do BIM, sendo utilizado para a verificação dos DWGs gerados, apresentação aos orientadores e utilizado ainda para a criação de detalhes específicos de cada projeto em 2D, que eram incorporados aos arquivos em Revit. 


\section{PROJETO PILOTO}

Localizado em uma cidade brasileira, o projeto referência trata-se de uma residência unifamiliar (Figura 2 e 3), que encontra-se em execução, com área construída de 243 metros quadrados contando com térreo, mais um pavimento e cobertura. O sistema construtivo foi de alvenaria convencional de tijolos com sistema estrutural de pilar e viga de concreto armado. O valor estimado da obra era de $\mathrm{R} \$ 400$ mil e o início do projeto se deu Maio/19, com o fechamento do contrato e finalizou-se em Janeiro/20 com o termo de finalização de projeto assinado pelo cliente.

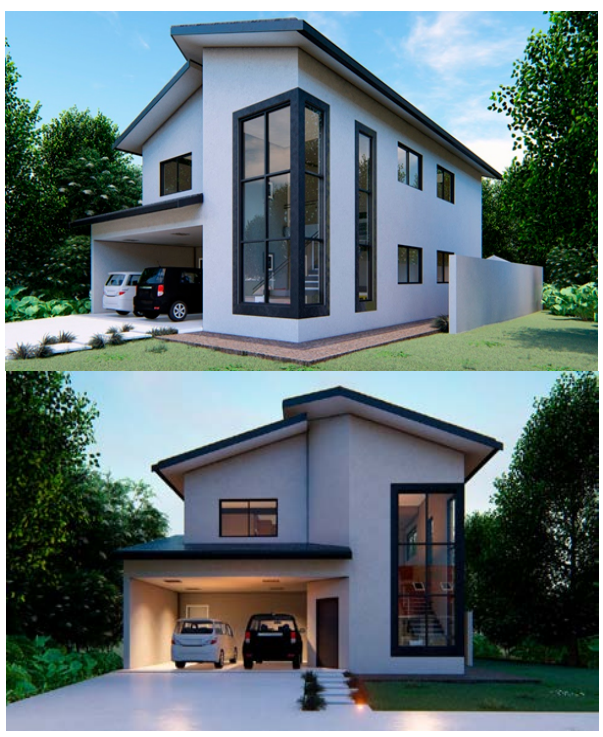

Figura 2 e 3: Perspectiva do projeto referência deste estudo

Embora a equipe envolvida não tenha formalizado um Plano de Execução BIM (BEP - BIM Execution Plan) para o projeto em questão, num primeiro momento antes do início dos trabalhos junto a todos os envolvidos no processo de projeto foram definidos os prazos, a forma que aconteceriam as trocas de informação entre os envolvidos, além da escolha do repositório onde seriam disponibilizados os arquivos dos modelos BIM. Para o projeto referência foram desenvolvidos os projetos: arquitetônico, estrutural, de instalações elétricas e instalações hidráulicas para água fria e quente, drenagem e esgoto e o cabeamento estruturado. Cada uma das equipes desenvolveu um modelo BIM específico da sua disciplina que foi posteriormente combinado num modelo central tendo como base o modelo fornecido pela equipe de arquitetura. A equipe responsável pela disciplina de arquitetura desde o início do projeto arquitetônico decidiu pela utilização de software BIM, neste caso optou-se pelo Autodesk Revit, atendendo à intenção de trabalhar com BIM desde o início dos trabalhos. Utilizou-se na fase de projeto de arquitetura o software Lumion para a renderização e apresentação do projeto ao cliente.

Optou-se pela utilização do Modelo federado dado que cada disciplina do projeto possuía seu próprio arquivo os quais eram vinculados entre si (Figura 4). Um modelo no software Revit pode se constituir de vários modelos vinculados individuais para se criar um modelo agregado de todos os dados (AUTODESK, 2019).

Tendo em vista a multidisciplinaridade do trabalho, cada equipe eventualmente utilizou softwares especializados de acordo com a necessidade específica de suas áreas, porém, de acordo com o previamente combinado para a modelagem BIM 3D da arquitetura, de todas as instalações e para o desenho estrutural as equipes utilizaram o Autodesk Revit em alguma etapa do desenvolvimento do modelos.

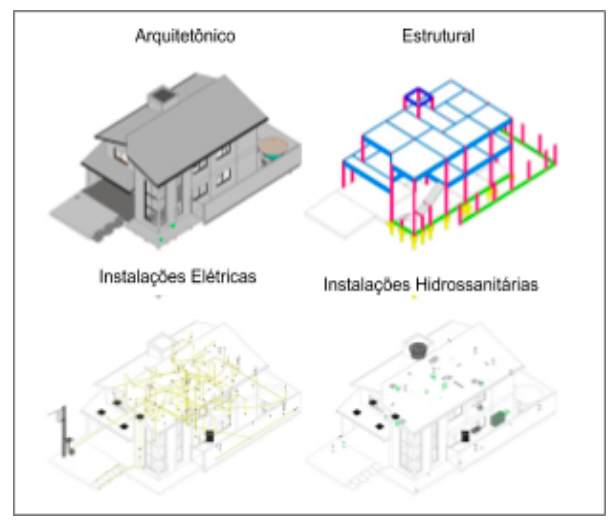

Figura 4: Modelos BIM

Com relação a utilização de softwares específicos, a equipe responsável pelo projeto estrutural utilizou o Cypecad e o Microsoft Excel para a elaboração do memorial de cálculo da estrutura de concreto. Essas informações foram, posteriormente, carregadas e consolidadas num modelo no Revit através de arquivos IFC. As equipes responsáveis pelos projetos de instalações elétricas e hidráulicas, exploraram as ferramentas MEP do software Revit, porém os cálculos para dimensionamento foram realizados no Microsoft Excel. Durante o trabalho dessas duas equipes o AutoCAD foi utilizado como ferramenta de apoio para a realização de estudos para os projetos de água fria e quente e de cabeamento estruturado, para posteriormente, serem modelados definitivamente no software Revit.

\section{PROCESSO DE PROJETO}

Atualmente a Engefour Jr desenvolve projetos até a etapa de projeto legal, sendo as fases de projeto divididas em: Levantamento de dados para arquitetura, programa de necessidades para arquitetura, estudo preliminar arquitetônico, anteprojeto arquitetônico e complementares, projeto legal e projeto executivo e complementares. $\mathrm{Na}$ Figura 5 tem-se o fluxo do processo geral de projeto utilizado pela equipe da EJ para o projeto referência.

Outra questão foram as fases de desenvolvimento do Modelo BIM, sendo estas conhecidas como Nível de Desenvolvimento (LOD - Level of Development). Conforme BIMFórum (2018), o LOD é o nível de desenvolvimento que descreve o grau de completude para o qual um elemento do modelo é desenvolvido. Os produtos de cada fase ou etapa do projeto precisam ser definidos sucintamente para que os membros da equipe 
entendam o nível de detalhe no qual eles devem trabalhar e quais decisões devem ou não estar finalizadas. Os níveis de desenvolvimento são representados em uma escala que neste caso varia em seis níveis correspondendo a um detalhamento que vai ocorrendo progressivamente ao longo do projeto: LOD 100 (fase conceitual), LOD 200 (geometria aproximada), LOD 300 (geometria precisa), LOD 400 (execução ou fabricação) e LOD 500 (obra concluída). Conforme Reis (2019) o LOD é uma referência importante para a especificação e articulação entre os envolvidos no projeto em relação a conteúdo e níveis de confiabilidade de modelos BIM. No desenvolvimento do projeto notou-se que os modelos foram passando por uma evolução à medida que eram detalhados e avançando as fases de projeto deixando claro para a equipe de projeto que o modelo foi sofrendo alterações nos diversos níveis de desenvolvimento: LOD 100, LOD 200, LOD 300 e LOD 350 sendo que esses foram associados às fases projetuais definidas pela NBR 16636-2:2017. Os modelos BIM do projeto de referência atingiram, portanto, o LOD 350 para todas as disciplinas.

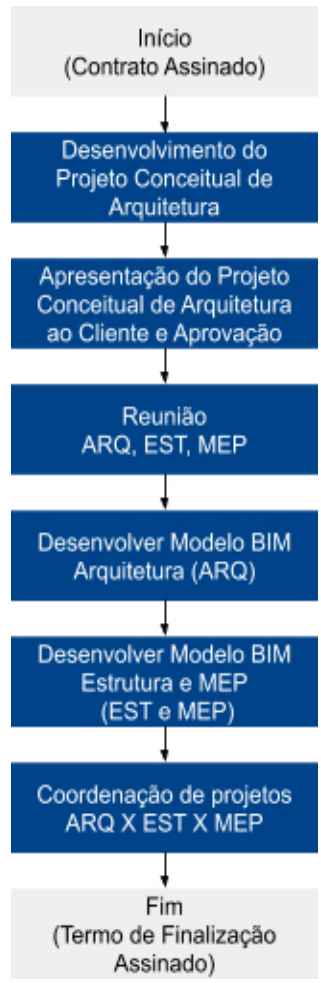

Figura 5: Fluxo de projeto

Para o processo de compatibilização, os modelos BIM foram separados por disciplinas e linkados no modelo principal de arquitetura onde os problemas de compatibilização eram identificados através de análise manual dos projetistas, principalmente de arquitetura. A detecção das interferências era feita pelo membro da equipe de arquitetura, que fazia a coordenação dos projetos e contactava o responsável de cada área para a resolução dos problemas (Figuras 6 e 7).
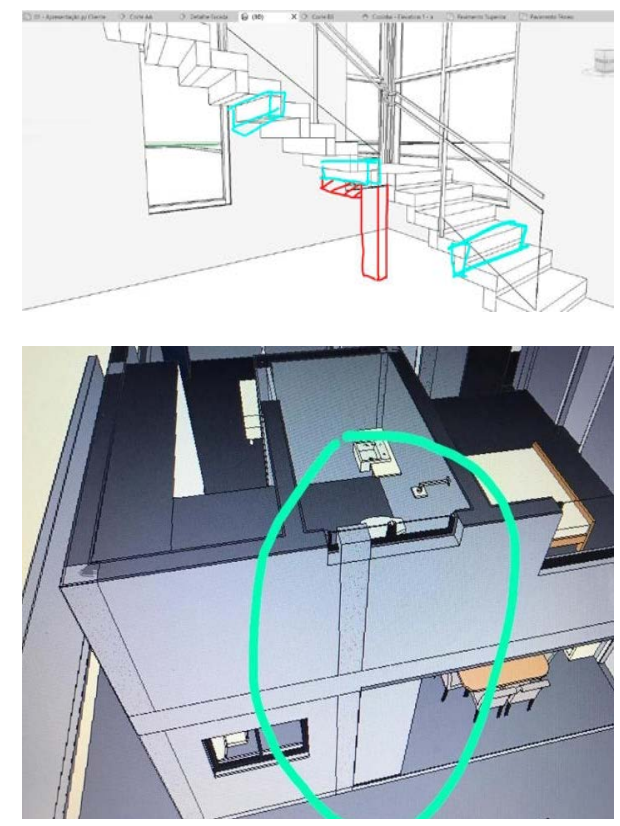

Figuras 6 e 7: Interferências nos modelos

A detecção de interferências tem por objetivo eliminar os conflitos espaciais do sistema antes da execução. Conforme ABDI (2017) a coordenação representa a vantagem de simular a construção virtual, trabalhando desta forma a prevenção e a correção de problemas antes da etapa de obra, que acarreta a redução de custo e desperdício, facilitando o atendimento ao cronograma de obra. Da detecção de interferências entre modelos, as respectivas equipes foram acionadas para que se discutisse a viabilidade de alteração nos projetos e, em seguida, os submetia a uma nova revisão. Nos casos de alterações de grande impacto era convocada uma reunião, que acontecia na sede da Empresa Júnior, sendo que, na maioria das situações, as discussões aconteciam através do aplicativo de mensagens instantâneas WhatsApp, sendo essa a única forma utilizada de registro das alterações e de onde seriam realizadas.

Como repositório dos arquivos do projeto de referência utilizou-se a ferramenta Google Drive, um serviço de armazenamento e sincronização de arquivos da Google, que baseia-se no conceito de computação em nuvem, sendo possível armazenar arquivos através e fazer upload a partir de qualquer computador ou outros dispositivos compatíveis, desde que esses estejam ligados à internet. Para isso, uma pasta na nuvem foi compartilhada por todos os projetistas e cada projetista deveria fazer upload do arquivo mais atualizado após realizadas as alterações definidas no processo de coordenação 3D. Esse procedimento de upload e download dos arquivos na nuvem era realizado no final de cada dia de trabalho ou conforme combinado entre os projetistas. Os formatos dos arquivos definidos para a realização dessas entregas dos modelos BIM foram os formatos nativos dos softwares de modelagem adotados para as entregas internas de cada equipe, portanto, arquivos DWG, RVT e C3E. Para a 
verificação de interferências e interlocução de modelos em geral foram utilizados arquivos IFC. A documentação do projeto foi elaborada a partir do modelo combinado, nesse caso, pranchas e tabelas em formato PDF que foram impressas e entregues ao cliente junto das imagens renderizadas. Todos os modelos dos projetos se encontram disponíveis à totalidade dos membros da empresa no repositório online, não sendo encaminhados ao cliente. Os arquivos salvos no Google Drive ficam disponíveis para os projetistas e futuros membros da empresa por tempo indeterminado (Figura 8).

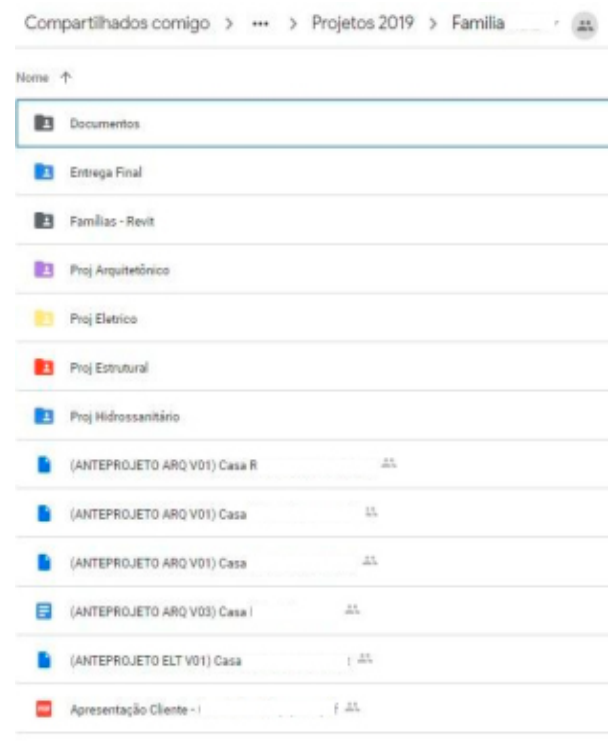

Figura 8: Arquivos no Google Drive

Outro ponto importante é a padronização da nomenclatura dos arquivos em BIM, visto que, além do aspecto organizacional, as diferentes disciplinas envolvidas fazem referência a arquivos de outras. Sendo assim, é importante seguir o estabelecido com relação às nomenclaturas evitando assim retrabalho e/ou confusão a respeito de qual arquivo é o mais atualizado. Conforme Carezzato (2018) deve-se considerar também a padronização da nomenclatura das bibliotecas utilizadas no modelo, bem como dos seus parâmetros, para garantir a extração adequada de informações desse. Na nomenclatura padrão da $\mathrm{EJ}$, os arquivos foram nomeados de acordo com o que segue abaixo:

\section{"(ANTEPROJETO ARQ V01) Projeto X"}

Indicava-se, portanto, a fase do projeto, a disciplina, o número da última revisão no arquivo e o nome do projeto geral. A nomenclatura era alterada quando se aumentava o nível de desenvolvimento do projeto, ou seja, quando passava para a próxima fase. Dessa forma, criou-se um banco de dados linear dos arquivos.

Previamente ao início das modelagens foram acordadas entre as equipes as seguintes definições: todos os modelos seriam desenvolvidos a partir do mesmo ponto base, e deveriam utilizar a mesma unidade de medida, nesse caso, metros. Também foi definido que durante as etapas de revisão todos os modelos seriam verificados em busca de componentes desvinculados dos níveis e eixos de referência, falhas na identificação dos componentes, elementos duplicados ou sobrepostos e inconsistências de maneira geral. Essas premissas e definições com relação a modelagem garantiram a qualidade e a confiabilidade das informações que foram extraídas posteriormente, evitando assim os conflitos existentes em uma mesma disciplina como por exemplo: elementos ou componentes

sobrepostos, duplicados, inseridos erroneamente, descrição e anotações nas tabelas e pranchas erradas.

\section{DISCUSSÃO}

Com relação aos softwares uma análise se faz importante pois até então os projetos arquitetônicos na EJ eram elaborados com apoio do AutoCAD na geração de documentação 2D em conjunto com o Sketchup, para visualização do projeto pelos projetistas em $3 \mathrm{D}$ e apresentação para o cliente. 0 processo de compatibilização até então era trabalhoso e consequentemente demandava muito tempo, além de ser de difícil compreensão devido a abstração característica da utilização de processo tradicional CAD. Na tentativa de minimizar esses problemas, definiu-se pela utilização de software BIM Revit para o exercício piloto tendo em vista que a maioria dos participantes já tinham algum conhecimento sobre as vantagens da utilização do software e gostariam de compreender mais sobre o assunto sendo a oportunidade da equipe de aprender e se aprofundar a partir de um projeto real.

Conforme Kensek (2018) softwares BIM operam com informações associadas ao modelo 3D, como uma base de dados, sendo estes elaborados para atendimento a diversos propósitos: projeto esquemático, desenvolvimento de design, documentação de construção e, às vezes, projeto "como construído" (as built).

As alterações com relação ao fluxo de projeto tradicional de projeto, que até então iniciava com o arquitetônico, sendo este desenvolvido até a fase de executivo individualmente, para somente então envolver os projetos complementares no processo foram muito significativas e atendeu aos objetivos almejados pela equipe do início do projeto tendo em vista que com o BIM, todos os profissionais e agentes do projeto foram envolvidos e consultados desde a concepção inicial do empreendimento, atingindo uma solução mais completa e compatibilizada. Essa decisão de utilizar o BIM foi discutida com os demais integrantes da equipe onde avaliou-se os objetivos a serem alcançados com o projeto para a EJ, sobretudo o de aprender a trabalhar de forma integrada e colaborativa junto com os responsáveis pelas disciplinas desenvolvidas. Outros fatores foram determinantes para a escolha desse software, sendo pois a disponibilidade de utilizar a licença estudantil, a interoperabilidade com outros softwares e a quantidade de material disponível na internet em caso de dúvidas.

Com relação às capacitações observou-se que seria interessante realizar um planejamento para formações regulares estruturados pelos membros da EJ que possuem maior experiência em dada ferramenta permitindo 
organizar os conteúdos de acordo com as necessidades reais da empresa e do processo de projeto. Esses cursos poderiam inclusive ser abertos à comunidade acadêmica promovendo a divulgação da empresa entre os demais discentes e docentes na universidade contribuindo com a qualificação destes que poderiam vir a ser futuros membros da EJ.

Percebeu-se que no processo BIM existe uma necessidade maior com relação a comunicação. Foi realizada através do aplicativo de mensagens instantâneas WhatsApp e email. O aplicativo foi utilizado como principal forma de comunicação entre os projetistas, sendo utilizado por todos os entrevistados para comunicar questões de projeto, avisar sobre a atualização dos arquivos em nuvem e para marcar reuniões presenciais periódicas. Isso facilitou a comunicação e acelerou a resolução de interferências.

De maneira geral, as equipes conseguiram alinhar os projetos, porém, observou-se a importância de registro formal com uma documentação efetiva dessas informações, bem como comunicar as alterações entre todos os membros envolvidos no projeto.

\section{CONCLUSÕES}

A experiência discutida neste artigo foi um desafio para a Empresa Júnior, especialmente com relação a alteração de rotina. No entanto, acredita-se que trabalhar de forma colaborativa e multidisciplinar são requisitos que alinham com a demanda de mercado de trabalho, pois leva em conta situações reais e práticas em que os discentes podem avaliar seus conhecimentos.

Os resultados permitiram compreender o desenvolvimento do projeto multidisciplinar e colaborativo mediado pelo BIM nesse ambiente e mais especificamente, em identificar aspectos potencializadores e limitantes do trabalho colaborativo em questão tendo em vista a relevância e importância do tema.

Como limitações e entraves observados no processo destacam-se, a validação de um grande volume de informações e dados vinculados à modelagem paramétrica e principalmente, o período de adaptação à metodologia $\mathrm{BIM}$, tendo em vista que a longa curva de aprendizagem refletiu na queda na produtividade inicial de algumas equipes visto que mais da metade dos participantes tinham pouco contato com o BIM no início do projeto, indicando inclusive a falta de divulgação do BIM pela universidade resultando em um atraso da mesma com relação ao assunto.

A utilização de BIM em instituições de ensino no Brasil ainda está longe do ideal. Ruschel já afirmava em 2014 que existia um descompasso quando se tratava da utilização do BIM no ensino nas universidades em comparação à sua aplicação em escritórios e construtoras pelo país. Infelizmente a realidade desta universidade ainda é essa: ausência de disciplinas que abordem o BIM na grade curricular nos cursos de graduação e falta de equipamentos e profissionais, técnicos e professores, capacitados para atuação nessa área.

Em busca de aprimorar as próprias habilidades técnicas e atualização no mercado de trabalho, os alunos recorrem à capacitações externas, pois os projetos pedagógicos dos cursos de graduação da instituição não atendem essa demanda. Aprendem apenas o software, ou seja, a ferramenta, mas não o BIM como um processo em sua totalidade. É importante destacar que a ação executada dentro da Engefour Jr. não representa a implementação plena da plataforma, mas sim uma experimentação inicial para sua incorporação nos dois ambientes, Universidade e Empresa Júnior

No geral, a experiência de utilização do BIM na Empresa Júnior foi muito proveitosa pois proporcionou contato e aprofundamento em um processo mais atual de projeto, colaborativo e integrado, cuja utilização vem sendo estimulada e crescendo na indústria AECO. Nesse sentido, as práticas desenvolvidas na EJ possibilitam que os alunos participem dessa experiência: desenvolvimento de um projeto de forma colaborativa utilizando o BIM, e acompanhamento de obra, aproximando-os da realidade do mercado de trabalho.

Este trabalho visa ainda divulgar o assunto para que discentes e docentes se aprofundem no tema, estabeleçam investigações e articulem modos de integrar o uso do BIM colaborativo às atividades projetuais na universidade, conectando a academia à indústria AECO através da adoção do BIM nas Empresas Juniores.

\section{AGRADECIMENTOS}

Agradecemos à Universidade Federal de Mato Grosso do Sul pelas condições oferecidas ao desenvolvimento deste trabalho, assim como de outros tantos, e especialmente ao grupo de pesquisa algo+ritmo por fornecer suporte teórico e experimental para esta pesquisa e para a elaboração deste artigo.

\section{REFERÊNCIAS}

Agência Brasileira de Desenvolvimento Industrial - ABDI. Coletânea GUIAS BIM ABDI-MDIC. Brasília, 2017.

Autodesk Help. (2019). Gerenciando Vínculos. Disponível em https://knowledge.autodesk.com/pt-br/support/revitproducts/learn-

explore/caas/CloudHelp/cloudhelp/2019/PTB/RevitCollaborate/files/GUID-C7094D06-D4C5-4CCB-8E7B5C8188EC3272-htm.html

Associação Brasileira dos Escritórios de Arquitetura - AsBEASP Boas Práticas em BIM. Fascículo 2. São Paulo: AsBEA, 2015.

Barison, M. B.; Santos, E. T. (2011) Atual cenário da implantação de BIM no mercado da construção civil da cidade de São Paulo e demanda por especialistas. In: Encontro de Tecnologia de Informação e Comunicação na Construção, 5. , 2011, Salvador. Anais... Salvador: FAUFBA.

Becerik-Gerber, B.; Gerber, D. J. \& Ku, K. (2011). The pace of technological innovation in architecture, engineering, and construction education: integrating recent trends into the curricula. Journal of Information Technology in Construction (ITcon), v. 16, p. 411-432. Disponível em: <http://www.itcon.org/2011/24>

BIMFORUM. Level of development specification, 2018. Disponível em < https://bimforum.org/LOD/>

BRASIL. Lei n. 13.267, de 06 de abril de 2016. Disciplina a criação e a organização das associações denominadas empresas juniores, com funcionamento perante instituições de ensino superior. Disponível em <http://www.planalto.gov.br/ccivil_03/_ato20152018/2018/Decreto/D9377.htm.> 
Carezzato, Gustavo Gonçalves. (2018). Protocolo de gerenciamento BIM nas fases de contratação, projeto e obra em empreendimentos civis baseado na ISO 19650. Dissertação (Mestrado) - São Paulo.

Checcucci, E.S. (2019). Teses e dissertações brasileiras sobre BIM: uma análise do período de 2013 a 2018. PARC Pesquisa em Arquitetura e Construção, v. 10, p. e019008. doi:https://doi.org/10.20396/parc.v10i0.8653708

Checcucci, E. S.; Pereira, A. P. C. \& Amorim, A. L. (2013). Uma visão da difusão e apropriação do paradigma BIM no Brasil TIC 2011. Gestão e Tecnologia de Projetos, São Paulo, v. 8, n. 1, p. 19-39. doi: http://dx.doi.org/10.4237/gtp.v8i1.232.

Eadie, R., Browne, M., Odeyinka, H., Mckeown, C. \& Mcniff, S. (2013). BIM implementation throughout the UK construction project lifecycle: An analysis. Automation in construction, v. 36, 145-151. doi: https://doi.org/10.1016/j.autcon.2013.09.001

Herr, C. M., \& Fischer, T. (2019). BIM adoption across the Chinese AEC industries: An extended BIM adoption model. Journal of
Computational Design and Engineering, v. 6, p. 173-178. doi: 10.1016/j.jcde.2018.06.001

Kensek, K. (2018). Building Information Modeling: BIM: fundamentos e aplicações, Rio de Janeiro, RJ: Elsevier.

Reis, L. L. (2019. Requisitos para Níveis de Desenvolvimento em modelos BIM. Dissertação (Mestrado). Lisboa, Portugal.

Ruschel, R.C. (2014). To BIM or not to BIM? III Enanparq: Arquitetura, Cidade e Projeto: Uma Construção Coletiva. Anais Do Encontro Da Associação Nacional De Pesquisa E Pós-graduação Em Arquitetura E Urbanismo, São Paulo, Sp, Brasil, 3: Recuperado de https://www.Researchgate.Net/Profile/Regina_ruschel/Public ation/282669890_to_bim_or_not_to_bim/Links/5617c8fb08ae 4780f241e131.P $\overline{d f}$

Ruschel, R. C.; Andrade, M. L. V. X.; Morais, M. (2013). O ensino de BIM no Brasil: onde estamos? Ambiente Construído. Porto Alegre, 2013, vol. 13, n. 2, pp. 151-165. ISSN 1678-8621. doi: http://dx.doi.org/10.1590/S1678-86212013000200012. 